\title{
Torque Response Improvement of Direct Torque Controlled Three-Phase Inverter Fed Induction Motor Drive
}

\author{
Deepa Francis ${ }^{1}$, Tomson Thomas $^{2}$, Shanooga Chandran ${ }^{3}$ \\ PG Student, Dept of Electrical and Electronics Engg, St. Joseph's College of Engineering and Technology, \\ Palai, India ${ }^{1}$ \\ Assistant Professor, Dept of Electrical and Electronics Engg, St. Joseph's College of Engineering and Technology, \\ Palai, India ${ }^{2,3}$
}

\begin{abstract}
Induction motors (IM) play a very important role in both daily life and industry, because of its reduced price, reliability in functioning and less requirement for maintenance. The IM drives controlled with the vector control method is widely used in industry. However, this control technique requires complex coordinate transformation, inner current control loop and accurate system parameters. But in Direct Torque Control (DTC) method, more accurate and speedy torque response is offered without such coordinate transformations, PWM pulse generation and current regulators. The speed controller in DTC-IM drive usually employs the conventional PI controller. But it has characteristic of non-linear saturation, which will make the control performance of the drive much poor. In order to enhance the drive performance, Anti-Windup PI controller is introduced which distinctly control the integral state by feed backing the output of the integrator to the input port of the integrator according to whether the controller output is saturated or not, which allows the system leave saturation soon, resulting in reduced overshoot and settling time of the system. This paper implements the DTC technique for voltage source inverter fed induction motor drive with the speed controller realized both using conventional PI and anti-windup PI controllers and the improved torque response is verified using MATLAB.
\end{abstract}

Keywords: Induction Motor, Vector Control, Direct Torque Control, PI Controller, Anti Windup PI Controller.

\section{INTRODUCTION}

The positive aspects of Induction Motor, like its simple construction, reduced cost, reliability and reduced cost is the reason why it is being widely used in industrial as well as domestic applications. Also, unlike the DC motor, it can be used in any hostile environment because the issues of sparking and corrosion do not exist. But while using an Induction motor in industrial drives, where for high performance is required, these advantages become superseded. Before the most advanced micro-controllers and high switching frequency semiconductor devices were introduced, DC motors were used in variable speed drives, because it has an inherent decoupling facility and independent control of torque and fluxing the motor. At present, by using modern high switching frequency power converters controlled by microcontrollers, the frequency, phase and magnitude of the input to an $\mathrm{AC}$ induction motor can be controlled and hence the speed and torque can be controlled. Even then, induction motor has the property of inherent coupling of flux and torque components; as a result it cannot give torque performance as perfectly as the DC motor.

There are broadly two types of control methods for induction motor namely, Scalar control and Vector control. The scalar control is based on relationships valid in steady state, i.e., only the magnitude and frequency of voltage, current and flux linkage space vectors are controlled. Thus, the scalar control does not act on space vector position during transients.

But, the vector control is based on relations valid for dynamic states, i.e., not only magnitude and frequency but also instantaneous positions of voltage, current, and flux space vectors are controlled [1].

In 1970s vector control (Field Oriented Control (FOC) scheme) was introduced with de-coupling of torque and flux for better performance of induction motor drive system. The objective of vector control is to simplify the IM control, so that they resemble the equations for separately excited DC motor. Decoupling of the two components of stator currents (flux and torque producing components) is achieved as in DC machines to provide independent torque control. But, the problem faced by FOC scheme is the complexity in its implementation due to its dependency on machine parameters and the reference frame transformations [2]. Later in 1984 in Japan, DTC was introduced by Takahashi and then in 1985 in Germany by Depenbrock [3].Unlike the traditional Vector Control (VC), DTC does not require coordinate transformation, PWM and position encoders. Hence, DTC is much simpler. Moreover, Both DTC and VC provide good dynamic response but DTC is less sensitive to the motor parameter variations.

This technique got its name because of the fact that, based on the errors between the reference and the calculated values of flux and torque, the inverter output voltage states are directly controlled so as to keep the torque and flux 
errors in between the prefixed band (Hysteresis band) limits [4].

In this paper, the concept of Direct Torque Control and mathematical model of induction motor are discussed. Also conventional control using PI and anti-windup PI control [5] in the speed controller of DTC induction motor drive in speed mode is being analyzed. Above stated control has been simulated using Matlab Simulink and comparison between these techniques are presented.

\section{BASIC CONCEPTS AND PRINCIPLES OF DTC}

Basically, what the DTC actually does is to directly control the stator flux linkage and electromagnetic torque of induction motor simultaneously, by appropriate selection of inverter switching modes. For this a switching table is used for selecting the optimum voltage vector, thus providing immediate response, and lower harmonic loses without the complex field orientation by controlling the flux and torque errors within respective flux and torque hysteresis band limits, with the optimum selection being made[4]. The DTC controller consists of hysteresis controllers for flux and torque to select the appropriate switching voltage vector in order to maintain flux and torque between the set upper and lower limits. The command stator flux and torque magnitudes are compared with the respective calculated values and the errors (difference) are processed through hysteresis band controllers. Thus, the torque control of the inverter fed induction machine is carried out by hysteresis control of magnitude of stator flux and torque where one of the six active and two zero voltage vectors of the inverter (Fig. 1) is selected.

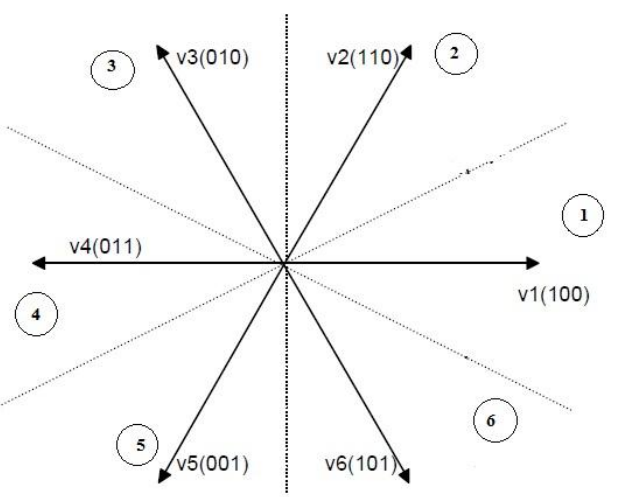

Fig.1. Example of an unacceptable low-resolution image

DTC induction motor drive has two modes of operation namely, torque mode and speed mode as shown in Fig. 2 and 3 respectively. In these figures two parallel paths are there, one for stator flux amplitude control and the other for the motor torque control. The two modes of operation of DTC mentioned above are on the basis of setting the torque reference. In torque mode controlled drive (Fig. 2), torque reference is an independent input. Whereas in speed mode controlled drive (Fig. 3) the torque reference is output of speed controller. For the closed loop control of stator flux and torque, the estimation of these quantities is required, for this the drive requires appropriate measurements like stator currents and voltage.
The estimation of stator flux and torque can be obtained from equations below.

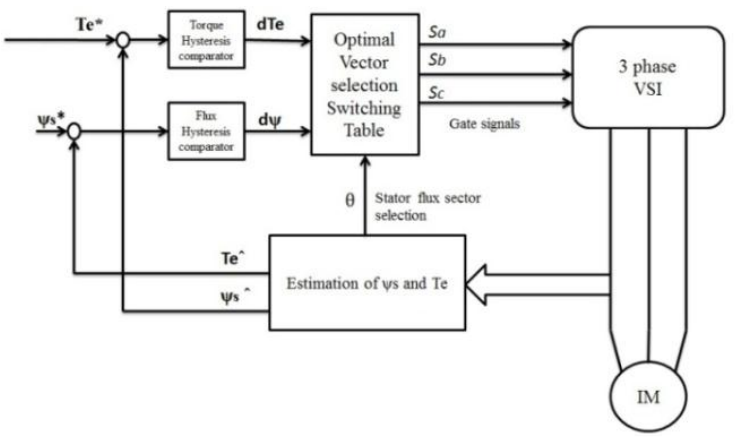

Fig.2. Control Scheme of a DTC Induction Motor Drive for Torque Mode of Operation

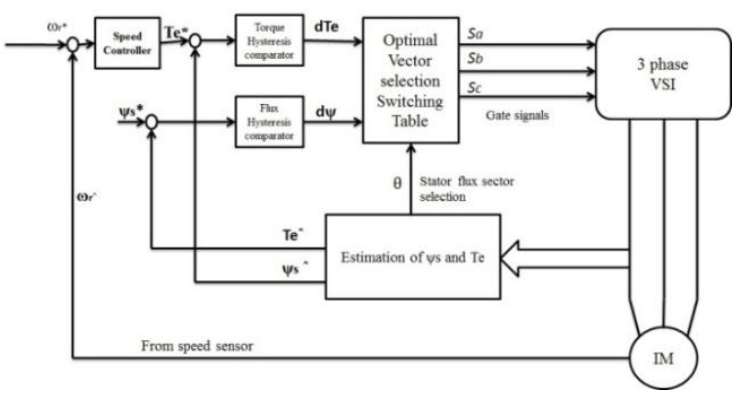

Fig.3. Control Scheme of a DTC Induction Motor Drive for Torque Mode of Operation

The stator flux of the motor can be found out by integrating the inverter output voltages and currents as:

$$
\begin{aligned}
& \Phi_{\mathrm{ds}}=\int\left(\mathrm{v}_{\mathrm{ds}}-\mathrm{R}_{\mathrm{s}} \mathrm{i}_{\mathrm{ds}}\right) \mathrm{dt} \\
& \Phi_{\mathrm{ds}}=\int\left(\mathrm{v}_{\mathrm{qs}}-\mathrm{R}_{\mathrm{s}} \mathrm{i}_{\mathrm{qs}}\right) \mathrm{dt} \\
& \Phi_{\mathrm{s}}=\sqrt{\Phi_{\mathrm{ds}}{ }^{2}+\Phi_{\mathrm{qs}}^{2}}
\end{aligned}
$$

The torque of the induction motor can be derived by currents and flux of the stator as below:

$$
\begin{aligned}
& \mathrm{Te}=\frac{3 \mathrm{P}}{4} \mathrm{~L}_{\mathrm{m}}\left(\mathrm{i}_{\mathrm{qs}} * \mathrm{i}_{\mathrm{dr}}-\mathrm{i}_{\mathrm{dr}} * \mathrm{i}_{\mathrm{qr}}\right) \\
&=\frac{3 \mathrm{P}}{4}\left(\mathrm{i}_{\mathrm{qs}} * \Phi_{\mathrm{ds}}-\mathrm{i}_{\mathrm{ds}} * \Phi_{\mathrm{qs}}\right)
\end{aligned}
$$

Where,

VDS and ids are the d-axis stator voltage and current in stationary reference frame.

Vqs and IQs are the q-axis stator voltage and current in stationary reference frame.

Rs is the stator phase resistance.

$\Phi_{d s}$ and $\Phi_{q s}$ are the $\mathrm{d}$-axis and the q-axis stator flux in stationary reference frame.

$\mathrm{Lm}$ is the mutual inductance between rotor and stator.

$\mathrm{P}$ is the number of poles of the motor.

A. Hysteresis Comparators

As it was already discussed, DTC is a hysteresis stator flux and torque control which directly selects one of the six 
nonzero and two zero voltage vectors generated by a VSI Using the switching table given in Fig. 6, it is possible to (Fig. 1), to maintain the stator flux and motor torque implement DTC schemes having good performance. within the hysteresis bands. The stator flux is controlled by a two-level hysteresis comparator. Thus the flux loop controller has two levels of digital output $(1,-1)$. Whereas the torque is controlled by a three-level hysteresis comparator. Thus the torque loop controller has three levels of digital output $(-1,0,1)$, as shown in Fig. 4 and 5, respectively.

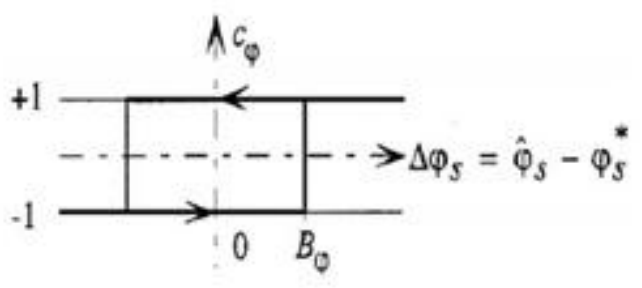

Fig. 4: Stator Flux Comparator

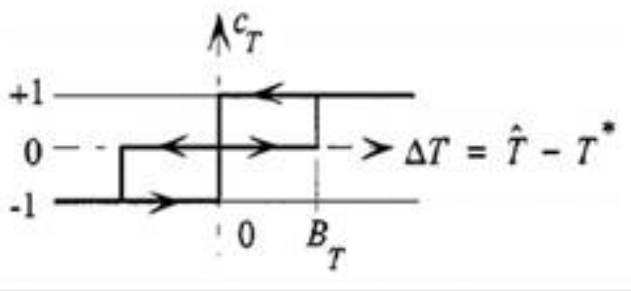

Fig. 5: Torque Comparator

\section{B. Switching Table}

The DTC switching table is implemented for the propers election of most appropriate VSI voltage vector at each sampling period, for maintaining the flux and torque within the hysteresis bands. The inputs for the switching table are: stator flux hysteresis comparator output, torque hysteresis comparator output and the space sector number of the stator flux. On the basis of these three inputs, an appropriate voltage vector will be selected according to the switching table given in Fig. 6.

For example, (refer to Fig. 1), let us consider the stator flux vector in sector1. For increasing the flux, voltage space vectors V2 and V6 has to be selected, while V3 and V5 for decreasing the flux. But among these, V2 and V3 for increasing torque, while V5 and V6 for decreasing torque. When the output of torque comparator is zero, i.e., torque doesn't need a change, then zero voltage vectors (V0 and V7) are selected, irrespective of the stator flux condition.

\begin{tabular}{|c|c|c|c|c|c|c|c|}
\hline \multicolumn{2}{|c|}{ Sector of Stator flux vector } & 1 & 2 & 3 & 4 & 5 & 6 \\
\hline \multirow{3}{*}{$\begin{array}{l}\text { Increasing Flux } \\
\qquad\left(C_{\Phi}=-1\right)\end{array}$} & $\begin{array}{l}\text { Increasing Torque } \\
\left(\mathbf{C}_{\mathrm{T}}=-1\right)\end{array}$ & $V_{2}$ & $V_{3}$ & $V_{4}$ & $V_{5}$ & $V_{6}$ & $V_{1}$ \\
\hline & $\begin{array}{l}\text { Holding Torque } \\
\left(\mathrm{C}_{\mathrm{T}}=0\right)\end{array}$ & $V_{7}$ & $\mathrm{~V}_{0}$ & $\mathbf{V}_{7}$ & $V_{0}$ & $\mathbf{V}_{7}$ & $V_{0}$ \\
\hline & $\begin{array}{c}\text { Decreasing Torque } \\
\left(\mathbf{C}_{\mathrm{T}}=+1\right)\end{array}$ & $V_{6}$ & $V_{1}$ & $\mathrm{~V}_{2}$ & $\mathbf{V}_{3}$ & $\mathbf{V}_{4}$ & $V_{5}$ \\
\hline \multirow{3}{*}{$\begin{array}{c}\text { Decreasing Flux } \\
\left(C_{\Phi}=+1\right)\end{array}$} & $\begin{array}{l}\text { Increasing Torque } \\
\left(\mathrm{C}_{\mathrm{T}}=-1\right)\end{array}$ & $V_{3}$ & $V_{4}$ & $V_{5}$ & $V_{6}$ & $\mathbf{V}_{1}$ & $V_{2}$ \\
\hline & $\begin{array}{l}\text { Holding Torque } \\
\left(\mathrm{C}_{\mathrm{T}}=0\right)\end{array}$ & $V_{0}$ & $V_{7}$ & $\mathbf{V}_{0}$ & $\mathbf{V}_{7}$ & $V_{0}$ & $V_{7}$ \\
\hline & $\begin{array}{l}\text { Decreasing Torque } \\
\quad\left(\mathrm{C}_{\mathrm{T}}=+1\right)\end{array}$ & $V_{5}$ & $V_{6}$ & $V_{1}$ & $\mathbf{V}_{2}$ & $\mathbf{V}_{3}$ & $V_{4}$ \\
\hline
\end{tabular}

Fig. 6: DTC switching table

\section{Matlab Simulink Model of DTC}

The Direct Torque Control logic is developed using Matlab and is shown in Fig. 7. The inputs to the block are stator flux error (difference between reference flux and estimated flux), torque error (difference between reference torque and estimated torque) and the stator flux for determining the stator flux sector number, the three of which form the inputs for the DTC switching table.

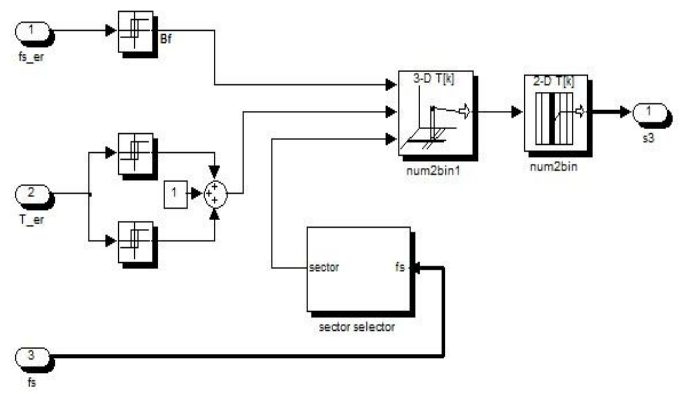

Fig. 7: DTC Simulink model

A three dimensional matrix is developed for implementation of switching table by MATLAB programmers which is called in by the simulink model during the simulation.

\section{III.MATHEMATICAL MODELING OF INDUCTION MOTOR}

In this modeling of induction machine, several ideal conditions are assumed, such as perfectly smooth air gap, Phase windings physically 120 degrees apart for both stator and rotor, winding resistance and leakage resistance assumed to be constant, iron loss and main flux saturation ignored. Therefore the induction machine considered is an ideal smooth air gap machine with perfectly sinusoidal distribution of windings with all the effects of MMF harmonics neglected.

The first step in mathematical modeling of ac induction machine is to define them as coupled stator and rotor polyphase circuits in terms of phase variables (stator currents ias, ibs, ics; rotor currents iar, ibr, icr) The second step is transformation from original abc reference frame to a common $\mathrm{dq}$ frame, where the voltages currents and fluxes are represented as 2-Dspace vectors.

The available selections of dq frames are:

a) Stator reference frame $\omega_{\mathrm{k}}=0$

b) Rotor reference frame $\omega_{\mathrm{k}}=\omega_{\mathrm{m}}$

c) Synchronous reference frame associated with the frequency $\omega_{\mathrm{s}}$ (possibly time varying) of the stator excitation.

Electrical system equations:

$$
\begin{aligned}
& V_{s}=i_{s} R_{s}+\frac{d f_{s}}{d x}+\omega_{k} M f_{s} \\
& V_{r}=i_{r} R_{r}+\frac{d f_{r}}{d t}+\left(\omega_{k}-\omega_{m}\right) M f_{r}
\end{aligned}
$$

Where space vector $\mathrm{fs}=[\mathrm{fds}$; fqs $]$ and $\mathrm{M}=$ rotational operator. 
Flux linkage equations:

$$
\begin{aligned}
& f_{s}=L_{s} i_{s}+L_{m} i_{r} \\
& f_{r}=L_{r} i_{r}+L_{m} i_{s}
\end{aligned}
$$

Therefore we can write:

$$
\begin{gathered}
i_{s}=\tau_{s} f_{s}-\tau_{m} f_{r} \\
i_{r}=-\tau_{m} f_{s}+\tau_{r} f_{r}
\end{gathered}
$$

Where,

$$
\begin{gathered}
L_{s}=L_{m}+L_{s l} \text { and } L_{r}=L_{m}+L_{r l} \\
\tau_{s}=\frac{L_{r}}{\Delta} ; \tau_{s}=\frac{L_{r}}{\Delta} ; \tau_{m}=\frac{L_{m}}{\Delta}
\end{gathered}
$$

Mechanical System Equations:

$$
\mathrm{T}_{\mathrm{e}}=\mathrm{J} \frac{\mathrm{d} \omega_{\mathrm{mec}}}{\mathrm{dt}}+\mathrm{B} \omega_{\mathrm{mec}}+\mathrm{T}_{\mathrm{L}}
$$

Where,

$$
\begin{gathered}
\mathrm{T}_{\mathrm{e}}=\frac{3}{2} \frac{\mathrm{P}}{2}\left(\mathrm{f}_{\mathrm{s}} \cdot \mathrm{i}_{\mathrm{s}}\right) \\
=0.75 \mathrm{P}\left(\mathrm{f}_{\mathrm{ds}} \mathrm{i}_{\mathrm{qs}}-\mathrm{f}_{\mathrm{qs}} \mathrm{i}_{\mathrm{ds}}\right)
\end{gathered}
$$

Nomenclature:

$\mathrm{V}=$ Voltage space vector

$\mathrm{f}=$ flux linkage space vector

$\mathrm{R}=$ Resistance

$\mathrm{L}=$ Inductance

$\tau=$ Inverse inductance

$\omega \mathrm{k}$ : speed of dq frame

$\omega \mathrm{m}$ : rotor speed

Te: electromagnetic torque

TL: load torque

$\mathrm{J}$ : moment of inertia

Subscripts:

s: Stator

r: Rotor

d: Direct axis

q: Quadrature axis

Here the mathematical model of three phase induction motor in stator reference frame is developed in Matlab environment based on the above equations. The Matlab Simulink for both electrical and mechanical model is implemented as shown in Fig. 8 and 9 respectively.

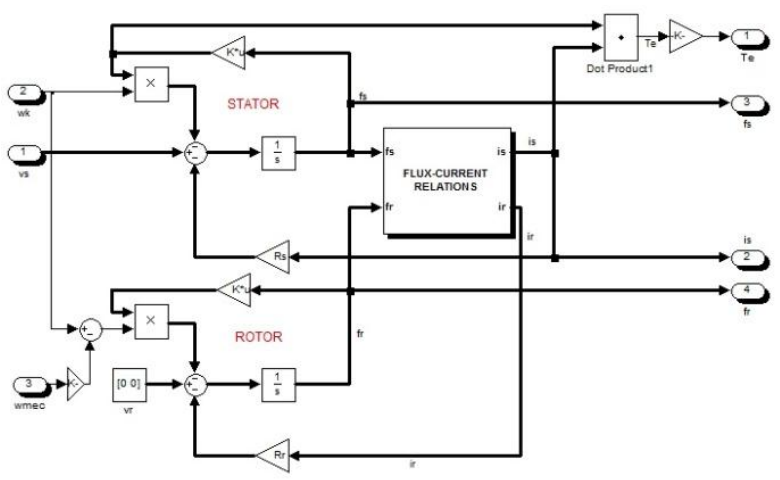

Fig. 8: Induction Machine Subsystem in Arbitrary Reference Frame.

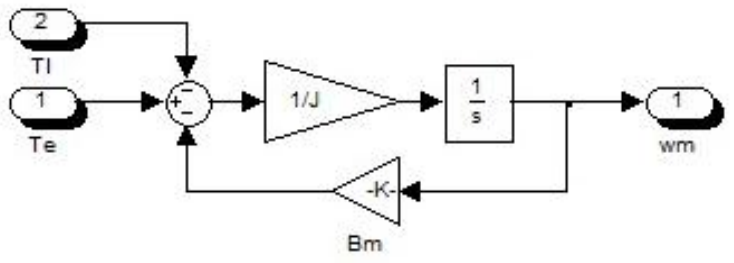

Fig. 9: Induction Machine Mechanical system

\section{IV.PI AND ANTI WIND-UP PI SPEED CONTROLLERS}

As mentioned earlier, the speed controllers are used in control scheme of a DTC induction motor drive for speed mode of operation (Fig. 3). Usually a PID controller is used as a speed controller where input is the error (difference) between the speed command (reference) and feedback speed (actual speed). Either a speed sensor or estimator can be used forgetting the actual speed for feedback. For simplicity, a PI controller can also be employed instead of PID. Furthermore, the use of antiwindup PI controller as speed controller further enhances the speed responses such as lower overshoot, reduced steady state error and faster time response [5].

When error input to the conventional PI controller is large, or if it remains non-zero for a long time, there arises an issue called PI controller windup or roll-over. The adverse effect of this issue is the controller output saturation because of large error or non-zero error resulting in accumulation of integrator output. This result in delayed response for any changes in the input and as the controller enters into deeper saturation level this delay will increase. Hence there arises the need for implementing an antiwindup strategy for preventing the controller from entering deep saturation and thus preventing the windup phenomenon.

\section{A. Conventional PI Controller}

Traditional PI controller is affected by the Windup phenomenon, its equivalent on the output side joined by a limiting function $\mathrm{T}_{\mathrm{e}}^{*}(\mathrm{u})$ (Equation: 13)

$$
\begin{gathered}
\mathrm{T}_{\mathrm{e}}^{*}(\mathrm{u})=\mathrm{T}_{\max } \operatorname{sgn}(\mathrm{u}),|\mathrm{u}|>\mathrm{T}_{\max } \\
=\mathrm{u},|\mathrm{u}| \leq \mathrm{T}_{\max }
\end{gathered}
$$

In the equation (13), $\mathrm{u}$ is the output of traditional PI controller, sgn (u) is the sign function. Fig. 10 shows the function of corresponding curve. Fig. 11 shows the PI controller with saturation limit.

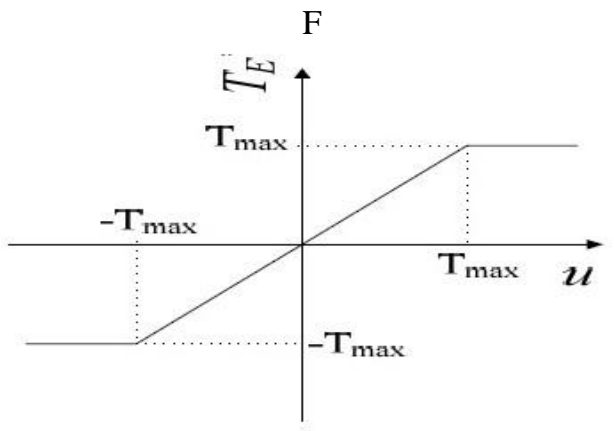

Fig. 10.The Function Curve of $\mathrm{T}_{\mathrm{e}}^{*}(\mathrm{u})$ 


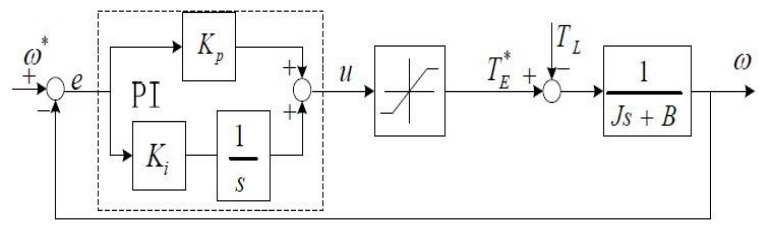

Fig. 11: Traditional PI Controller Structure with a Saturation Limit

\section{B. New Anti Wind-up PI Controller}

To prevent the saturation phenomenon, a new type of Anti -Windup PI controller is introduced, Fig. 12 shows the control block diagram. Accordingly, when $\mathrm{u}=\mathrm{T}_{\mathrm{E}}$, switch $S_{1}$ will be closed, $S_{2}$ will be opened therefore the controller becomes the typical PI controller. When $u>T_{E}$, switch $S_{2}$ will be closed, $S_{1}$ will be opened.

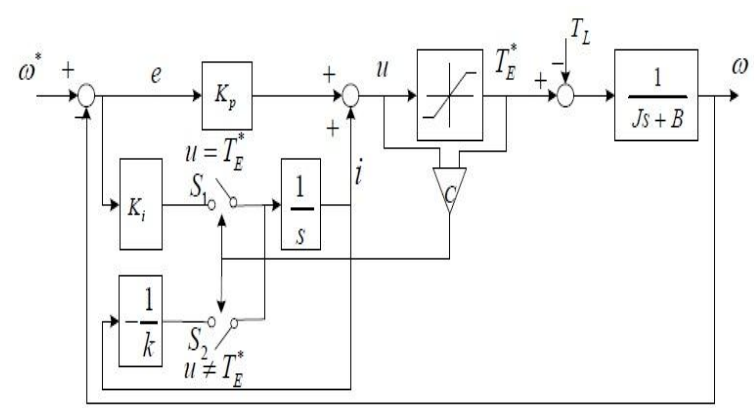

Fig. 12: The New Anti-Windup PI Controller Structure

The output gets multiplied by a coefficient and given as negative feedback to the input so that the integral output converges to zero rapidly.

\section{SIMULATION AND RESULTS}

The complete Simulink model of Direct Torque Controlled Induction motor drive in Speed mode is shown in Fig. 13.

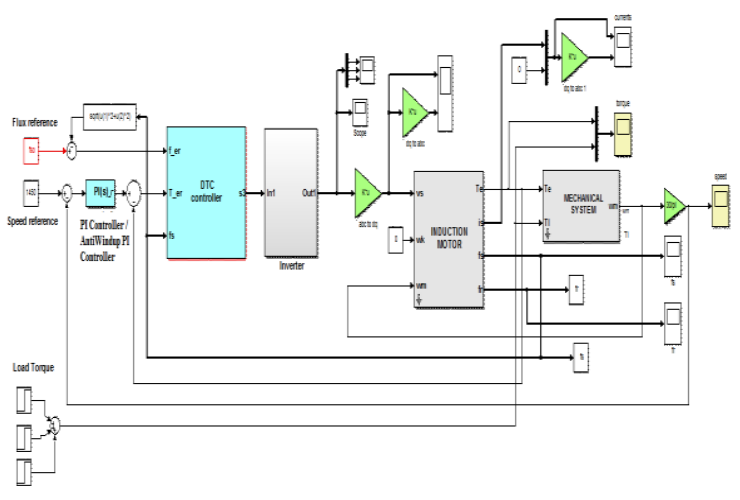

Fig. 13: DTC IM Drive Simulink Model

In this speed mode of DTC, both PI and anti-windup PI schemes are established in the speed controller block and the simulation results are compared.

C. Simulation Results

The waveform of developed electromagnetic torque of IM with the application of load torque of $9 \mathrm{Nm}$ at $0.3 \mathrm{sec}$ in the DTC simulink model with PI and anti-windup PI controllers are given in Fig. 14 and 15. Also the comparison of above two is given in Fig. 16. The comparison shows the improved torque response of the system when using the anti-windup PI controller.

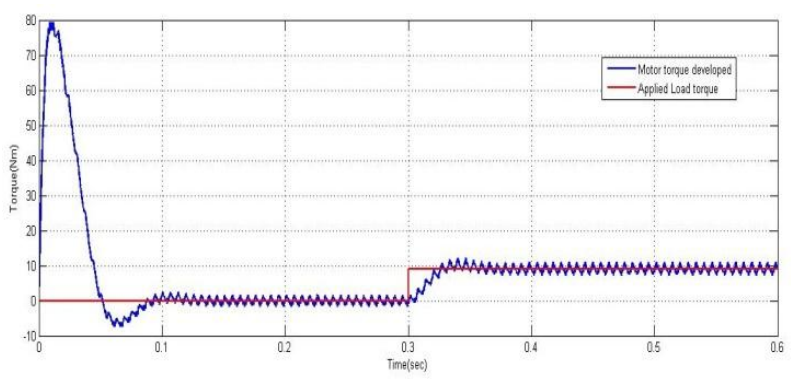

Fig. 14: Torque Response of Motor with PI Controller

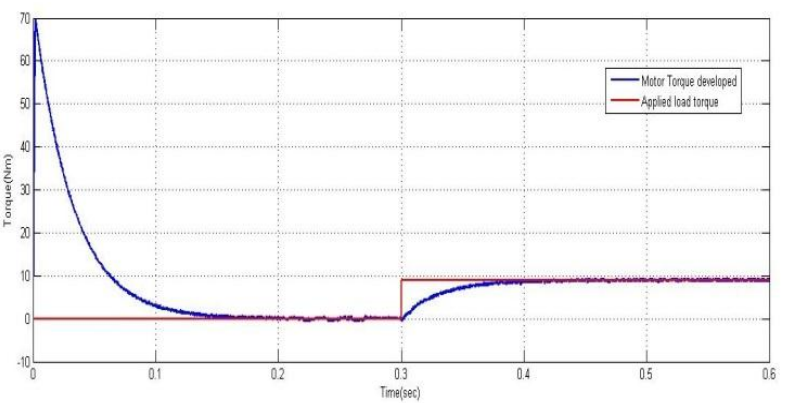

Fig. 15: Torque Response of Motor with Anti-Windup PI Controller

The comparison of speed response of IM with PI and anti wind up PI for a set speed of $750 \mathrm{rpm}$ is also shown in Fig. 17.

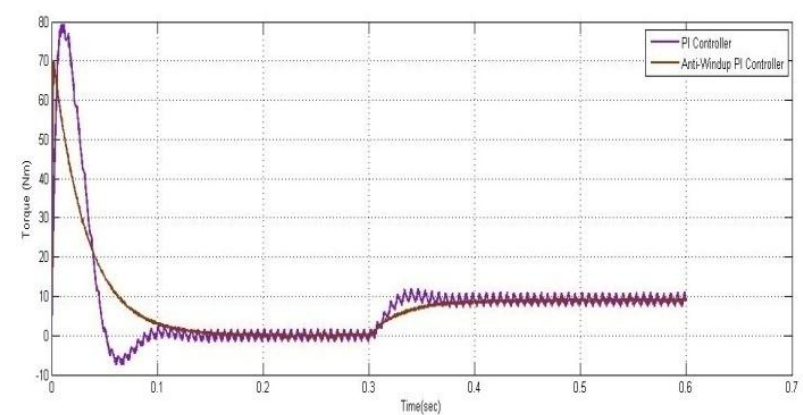

Fig. 16: Torque Response Comparison

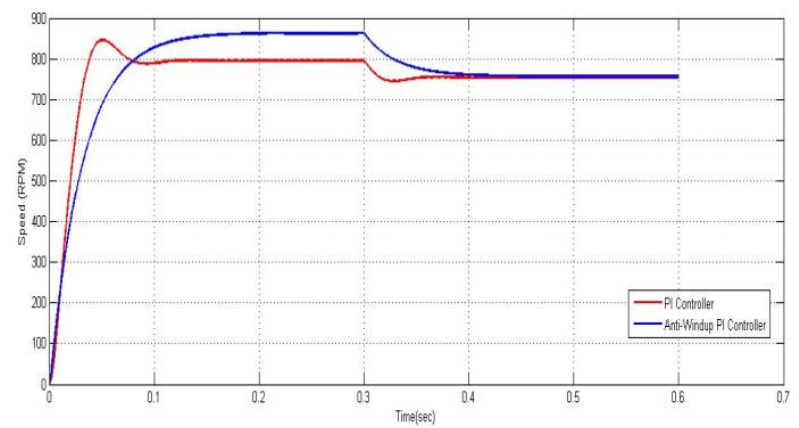

Fig. 17: Speed Response Comparison with speed set at 750 RPM 
The three inputs (Flux comparator output, Torque Comparator output and the Stator flux sector number) and the Voltage vector output of switching table for a particular time period is demonstrated in the Fig. 18.
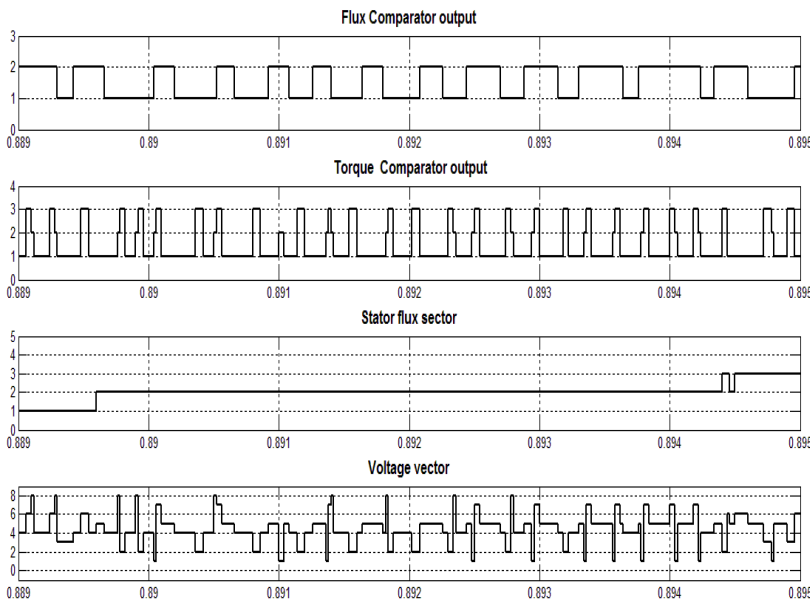

Time (sec)

Fig.18. Inputs and output of Switching Table

The inverter output voltages, stator currents (abc and dq components) and also the flux trajectory for a speed setting of $750 \mathrm{rpm}$ and a stepwise applied load torque is shown inFig. 19, 20 and 21 respectively.

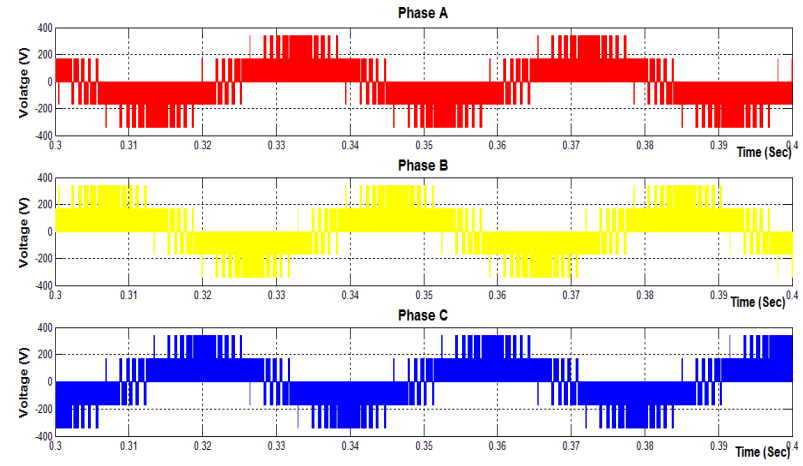

Fig. 19: Inverter Output Voltage
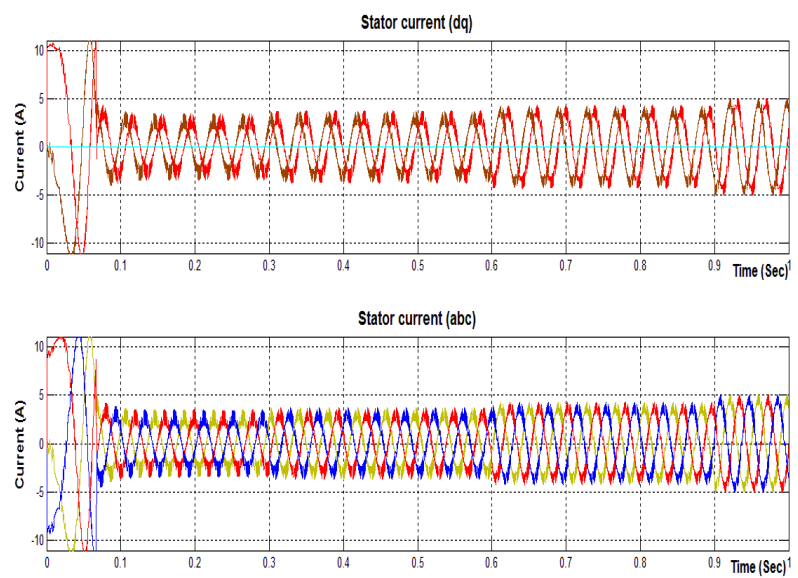

Fig. 20: Stator Current

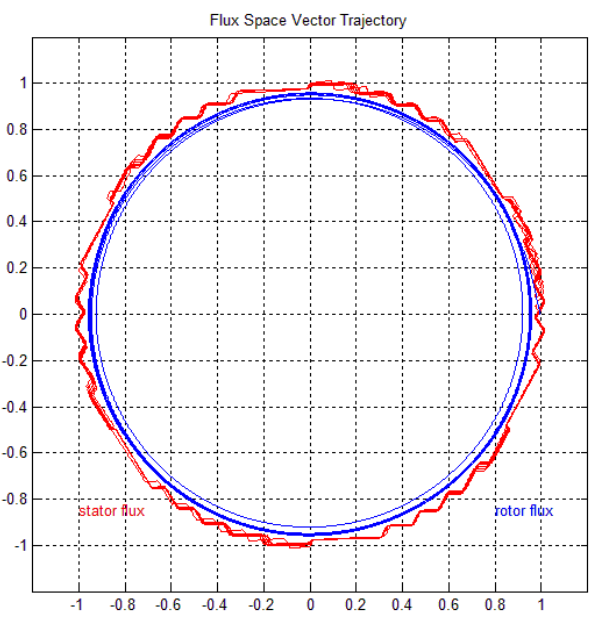

Fig. 21: Flux Space Vector Trajectory

\section{VI.CONCLUSION}

Complete MATLAB simulation of DTC-IM drive is developed and discussed in this paper. The Simulink submodels have been designed for the different components of the DTC scheme. The simulation results agree with the basic concepts of this DTC technique. It can be seen that the locus of the stator flux fall within the hexagon boundary created by six active voltage vectors. Whenever there is a change influx, the space vector switching are chosen such that the flux error remains within the band of the controller. Also a three phase IM mathematical modeling have been done in arbitrary reference frame. The DTC model developed has been tested and evaluated on this IM model. The outcomes of the simulation have demonstrated a very high accuracy in flux and torque independent control.

\section{REFERENCES}

[1] G.Kohlrvsz, D. Fodor, "Comparison of scalar and vector control strategies of Induction motor," Hungarian Journal of Industrial Chemistry, VESZPREM, Vol.32(2)pp.265-270(2011)

[2] DomenicoCasadei, Member, IEEE, Francesco Profumo, Senior Member, IEEE, Giovanni Serra, Member, IEEE, and Angelo Tani, "FOC and DTC: Two Viable Schemes for Induction Motors Torque Control," IEEETRANSACTIONS ON POWER ELECTRONICS, VOL. 17, NO. 5, SEPTEMBER 2002.

[3] Isao Takahashi, Member, IEEE, and Toshihiko Nougchi,"A,"A New Quick-Response and High-Efficiency Control Strategy of an Induction Motor," IEEE TRANSACTIONS ON INDUSTRY APPLICATIONS, VOL. IA-22, NO. 5. SEPTEMBER/OCTOBER 1986.

[4] TapajitGhosh, SumanDebnath, Priyanath Das,'Development and Implementation of Direct Torque Control for Three Phase Induction Motor Drives," International Journal of Advanced Scientific and Technical Research Issue 3 volume 1, January-February 2013.

[5] AnirbanGhoshal and Vinod John Department of Electrical Engineering, Indian Institute of Science, Bangalore,"Anti-windup Schemes for Proportional Integral and Proportional Resonant Controller", NATIONAL POWER ELECTRONIC CONFERENCE 2010 . 